\title{
Study the Effects of Spring Back on Sheet Metal Bending using Mathematical Methods
}

\author{
Dametew AW ${ }^{1 *}$ and Gebresenbet $\mathrm{T}^{2}$ \\ ${ }^{1}$ School of Mechanical Engineering, Kombolcha Institute of Technology, Wollo University, Germany \\ 2Industrial Engineering, Saint Mary's University, San Antonio, Texas USA
}

\begin{abstract}
In this study mathematical analysis of spring back was done for optimization of sheet metal bending process. The influence of sheet metal thickness, sheet metal type, friction, tool radius and tool shape on spring back for Aluminium, copper, mild steel and High strength steels, sheet metal have been used as variable to conducted this study. Since, the effects of each variable on the formation of spring back on sheet metal forming are investigated the following way. This empirical result shows that increasing sheet metal thickness from $0.8 \mathrm{~mm}$ to $4.5 \mathrm{~mm}$ the spring back is reduced $16 \%$ and $20.35 \%$. When increasing of sheet metal strength spring back increases because spring back of the sheet should depend on the yield strength of the material. As the materials yield strength increase the spring back after un-loading condition also increases. The effects of material type as shows that, using Aluminium sheet metal instead of high strength sheet metals spring back is reduced by $56 . \%$. Also, for decreasing of the tool radius leads reducing spring back. Spring back of deferential die $12 \%$ lower than edge bending die. In addition to these, if increasing the friction coefficient from 0.01 to 0.50 the spring back also increases by $52 \%$ because of increasing of friction force and this force generates higher amount of spring back. Thus the effects of material type, tool geometry, working condition and the thickness of sheet metal types were studied and investigated. Since, ultimately utilizing and compensation of tool is considered for prevention of spring back and optimizing of sheet metal bending process as well.
\end{abstract}

Keywords: Sprint back; Sheet metal; Banding process; Effects; Mathematical analysis; Optimization; Variables and effects

\section{Introduction and Back Ground}

Sheet metal bending is one of the most widely applied sheet metal forming operations. According to Prabhakar, et al. [1] bending of sheet metal is one of the widely used in industrial process, especially in automobile and aircraft industries, sheet metal bending is one of the most widely applied sheet metal forming operation. The bending process includes larger deformation of the structure either with temperature or without temperature application. But in the every mechanical process certain defects exists due to the inherent resistance property of the material for forming it to the required shape. Although the bending processes are accompanied by strains that are due to the instability phenomena which accompany the processing. These instability phenomena occur during the bending process (the cracking, deformation, the breakage) as well as after the bending process (the bowing). Though, one type of defect is spring back and is very important phenomenon which makes the object non suitable in case of rigid requirements. Spring back is mainly due to Bauchigner effect which allows the material to follow different paths during loading and unloading cycles. On the other hand Quality and success of the bending product depends upon the operating parameters as well as, material properties, material type, working condition, clearance, geometry of the die and punch, friction condition etc. In ancient times, sheet metal bending processes and bending quality are dependent on the designer's experience and involve trials and errors to obtain the desired result. All forming process will take places in the plastic region. So to analyze or to estimate spring back, nonlinear material properties which will accommodate stress strain relations in the nonlinear regions are required.

Many analytical models are proposed to study spring back in bending by using simple beam or plate bending and these models use a simplified assumption.

Spring back is a main defect occurred in the sheet-metal forming processes and has been thoroughly studied by researchers. The prediction of spring back has challenging for a variety of reasons, including numerical sensitivity, physical sensitivity, and poorly characterized material behavior under reverse loading and unloading conditions. In the previous time, quite a few efforts have been made to obtain a deep understanding of the spring back phenomenon. But till now the problem of spring back on sheet metal product is there. However this study is intended to analysis the effect of spring back using mathematical analysis, by considering tool geometry, material type, friction condition, working condition and sheet metal type were considered so as to improve spring back effect and optimize sheet metal bending process.

\section{Research Methodology}

In this study from the beginning to accomplishing result and till to reach the conclusion, the study was conducted through Empirical/. mathematical analysis from the data was collected primary source, literature review of research articles, books, magazines, manuals, company report and electronic-sources which are discuss related to bending process, sheet metal forming, sheet metal forming variables, the effects and science of spring back and mechanics of sheet metal forming process. Since, the study considered attempts to explore, analysis and discuss the effects of sheet metal type, sheet metal

*Corresponding author: Alie Wube Dametew, Technische Hochschule Nurnberg Georg Simon Ohm Nürnberg, Germany, Tel: +251913032751; E-mail: wubealie@gmail.com

Received September 15, 2017; Accepted October 16, 2017; Published October 26, 2017

Citation: Dametew AW, Gebresenbet T (2017) Study the Effects of Spring Back on Sheet Metal Bending using Mathematical Methods. J Material Sci Eng 6: 382. doi: 10.4172/2169-0022.1000382

Copyright: (c) 2017 Dametew AW, et al. This is an open-access article distributed under the terms of the Creative Commons Attribution License, which permits unrestricted use, distribution, and reproduction in any medium, provided the original author and source are credited. 
thickness, working condition/effects friction and the impacts of tool geometry on spring back formation to bending processes were studied. Followed by the solutions and the actions to be done on the reduction of sheet metal bending effect and bending processes optimization were done based of the empirical and literature survey results. In conclusion the conclusion and recommendation of the study is done. Since for the results of empirical analysis (Figure 1).

\section{Literature Review}

Literature review shows that considerable amount of researches have been reported in, modeling and analysis of sheet metal bending process are considered. The following relevant areas are reviewed:

(a) Sheet metal bending and mechanics of spring back.

(b) Modeling of sheet metal bending process, sheet metal type, and methods are clearly and briefly credible reviews of previous important literatures are briefly discussed here.

A number of researches have been carried out on the sheet metal bending processes and the effects of spring back. Anderson [2] analyzed the spring back behavior and prediction of Advanced High Strength Steel both numerically and experimentally The effect of friction condition on spring back can be considered by Kim and Koc [3] higher friction condition increases the tension applied to the sheet and decreases the required bending moment for a given curvature. Higher friction coefficient between the blank and tooling almost eliminated the stress variation in the thickness direction and reduced the spring back amount. Consequently, it is recognized that higher restraining force on the blank (i.e., higher friction or higher blank holder force is preferred to reduce the spring back in warm forming. They also show that higher values of blank holder force and friction have a negative effect on the formability of lightweight materials. They conclude that for the practical and wide application of warm forming to industrial cases, a compromise or appropriate control scheme is required in determining the optimal values of friction factors. Kim and Koc [3] investigated the effect of temperature gradients on the final part quality (i.e., spring back) in warm forming of lightweight materials. In order to extensively investigate the spring back behavior of an aluminum alloy after forming at elevated temperatures, an implicit FEA model taking into account the temperature effect during forming and un-loading was developed for simple 2D channel drawing process. Behrouzi et al. [4] presented a spring back analysis approach based on inverse modeling of spring back from target shape. The presented approach could be applied in a process design trend for producing the target shape after spring back. The presented approach is verified for symmetric and asymmetric bending processes. For defining the required conditions for inverse process modeling, an optimization trend is needed. An optimization algorithm for compensating spring back error and iterative tool design is presented based on inverse modeling. Kazan, et al. [5] study the effects of geometrical parameters and material hardening characteristics on the amount of spring back in bending process was presented and also, the prediction of spring back is developed by using neural network. Kadkhodayan the influence of blank holder force on spring back studied two materials, i.e Aluminum and steel sheet. To investigate the relation between the spring back and blank-holder force in U-bending process by means of the finite element program, using ABAQUS [6]. Through the finite element method by means of ABAQUS Simulations was performed. It was found that enlarging the blank holder force did not always guarantee the reduction of spring back and the middle values can increase the spring back. Safaeia et al. [7] was developed investigations on the effect of mechanical anisotropy of the spring back formation in advanced high strength steel sheet metal. Siswanto and Omar [8] proposed automatic mesh generator to create a numerical method to compensating the spring back by using an inverted spring back prediction so called spring- forward to optimize new tooling geometry surfaces. An optimization method to modify the geometry surfaces of the tooling dies based on spring forward simulations assisted by an automatic surface generator. Having seen nearly all the pertinent literatures we can conclude that a lot of research is being done on spring back by considering a few variables. Not much is done by using different factors for the prediction of spring back. In addition to deformation variables review from the literature but also there were limitations on the method for instance; some use manual computation /analytical methods/ and the other use numerical methods for spring back analysis. Despite the fact that effects of spring back prediction have employed by considering various parameters involved to use analytical method to solve such problems thus finite element analysis has been developed for prediction of spring back.

\section{Results and Discussions}

This section is developed for the discussion and analysis of the results obtained in the Conducted numerical and Analytical investigations.The developed model is used prior to implementation by utilizing different analyses to examine the effect of each parameter in the sheet metal bending process. The analysis conducted to examine the effect on the process is using the following ways

1. Conducting analysis in the developed mathematical/ analytical model to analyze and investigate the effect of each parameter.

2. Analytical predictions are compared with the previous studies and then, optimization process is done.

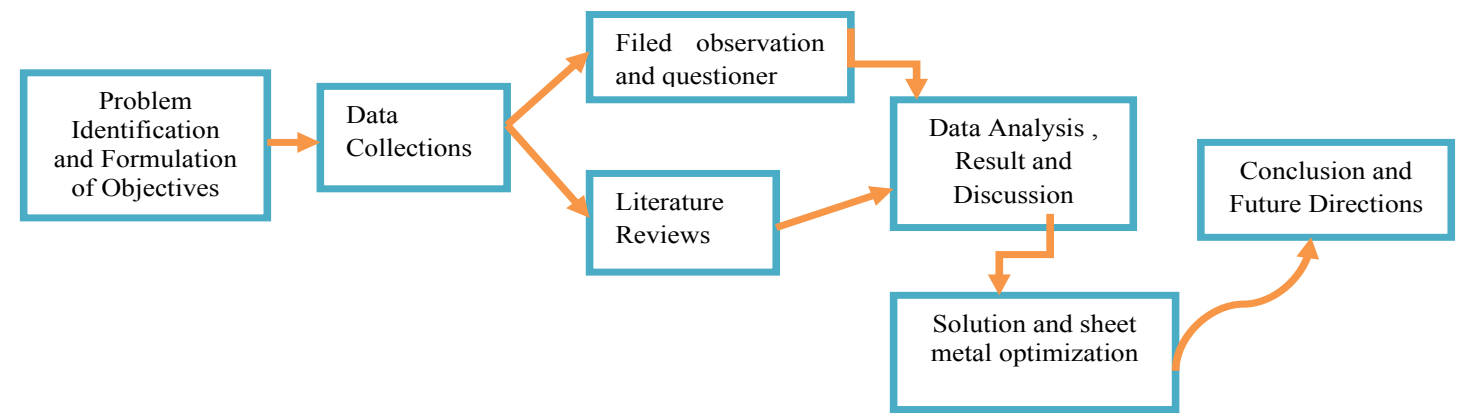

Figure 1: Research Methodology Frame work. 


\section{Parameters influencing prediction of spring back}

The effect of sheet metal type, sheet metal thickness and tool geometry of spring back prediction are discussed in this section.

Effect of sheet metal type: In order to evaluate the effect of $\mathrm{Al} 6001$ Aluminium alloy, Copper, Mild steel, High strength steel sheet metal blank thickness upon the resulting spring back prediction, four sheet metal thickness values of $0.8 \mathrm{~mm}, 1.5 \mathrm{~mm}, 3.3 \mathrm{~mm}$, and $4.5 \mathrm{~mm}$ were chosen. The relation between the spring back and material properties can affect the materials' applicability in production. In ductile materials, the spring back is much lower than in hard metals, with dependence on the modulus of elasticity (also called Young Modulus) of a particular material. The amount of spring back increases with greater yield strength materials. For instance, aluminum, copper, mild steel and high strength steels have exhibit different range of spring back characteristics. The obtained Analytical results of spring back radius of wiping die bending sheet metal is different for these four different materials, i.e. aluminum, copper, mild steel and high strength steels. As it can be observed in Table 1 and Figure 2 with constant sheet metal thickness, the aluminum have lower spring back than the other three sheet metal type i.e. Aluminum $<$ Cooper $<$ Mild steel $<$ high strength steel (HSS). When the spring back bending radius increases the material exhibits more spring back than the lower bend radius. From our bend radius result shows in Table 1; Aluminum have lower spring back radius than copper, mild steel and high strength steel. Hence the spring back is reducing from high strength steel (HSS) to Aluminum. On the other hand spring back increases moving from $(\mathrm{Al}<\mathrm{Cu}<\mathrm{MS}<\mathrm{HSS})$ sheet metal.

$$
\frac{R i}{R f}=4\left(\frac{R i \sigma y}{E T}\right) 3-\left(\frac{R i \sigma y}{E T}\right)
$$

Effect of sheet metal thickness: Sheet metal thickness is one of the parameters that clearly affect spring back in sheet metal forming which in fact may be utilized to control it. On the other hand, increasing the sheet metal thickness causes increasing of required punch load. So therefore, finding the optimum value for sheet metal thickness is vital importance for the purpose of using suitable values in the design stage. The relation between the value of blank thickness and bending radius is displayed. In the case of sheet metal forming process with different sheet metal thickness the bending radius gap increases, the spring back also increases. On the other hand the bending radius gap is small the spring back decrees. In such a way that our analysis is performed by using four sheet metal thicknesses, i.e. $0.8 \mathrm{~mm}, 1.5 \mathrm{~mm}, 3.3 \mathrm{~mm}$ and $4.5 \mathrm{~mm}$. Figure 3 and Table 2 shows that when increasing sheet metal thickness from $0.8 \mathrm{~mm}$ to $4.5 \mathrm{~mm}$ the bend radius gap is decrease. This implies that the spring back is decrease with increasing of sheet metal thicknesses. The results clearly verify that using larger blank thickness in the process leads reducing the amount of spring back. We are investigating from the analysis with increasing the blank thickness from $0.8 \mathrm{~mm}$ up to $4.5 \mathrm{~mm}$, within these range $16 \%$ of spring back is reduced.

Effect of Die radius and bending angle: The forming radius of punches and dies determines the size of the plasticized area created by the bending process. The proper die radius should be selected in proportion to material thickness, the lower the $\mathrm{R} / \mathrm{t}$ ratio, the more stress it generates in the formed material. With more stress, the strain hardening becomes substantial and a demand for the forming force increases. Breakage of parts occurs where by the bending force reaches the limits of the material. It is found that decreasing the die radius causes the reduction of spring back which means less variation in amount of $\theta$. Therefore, decreasing the die radius up to a limit value would guarantee the reduction of spring back. The reason of this fact, spring back reduced by decreasing the die radius, may be attributed to

\begin{tabular}{|l|c|c|c|}
\hline Sheet metal type & Thickness $\mathbf{( m m})$ & $\mathbf{R i}=\mathbf{2 t} \mathbf{( m m )}$ & 1.6 \\
\hline Aluminum & 0.8 & 1.6 & 0.557 \\
\hline Copper & 0.8 & 0.86 \\
\hline Mild steel & 0.8 & 1.6 & 1.32 \\
\hline High strength steel & 0.8 & 1.6 & 1.333 \\
\hline
\end{tabular}

Table 1: The effect of sheet metal type for spring back formation.

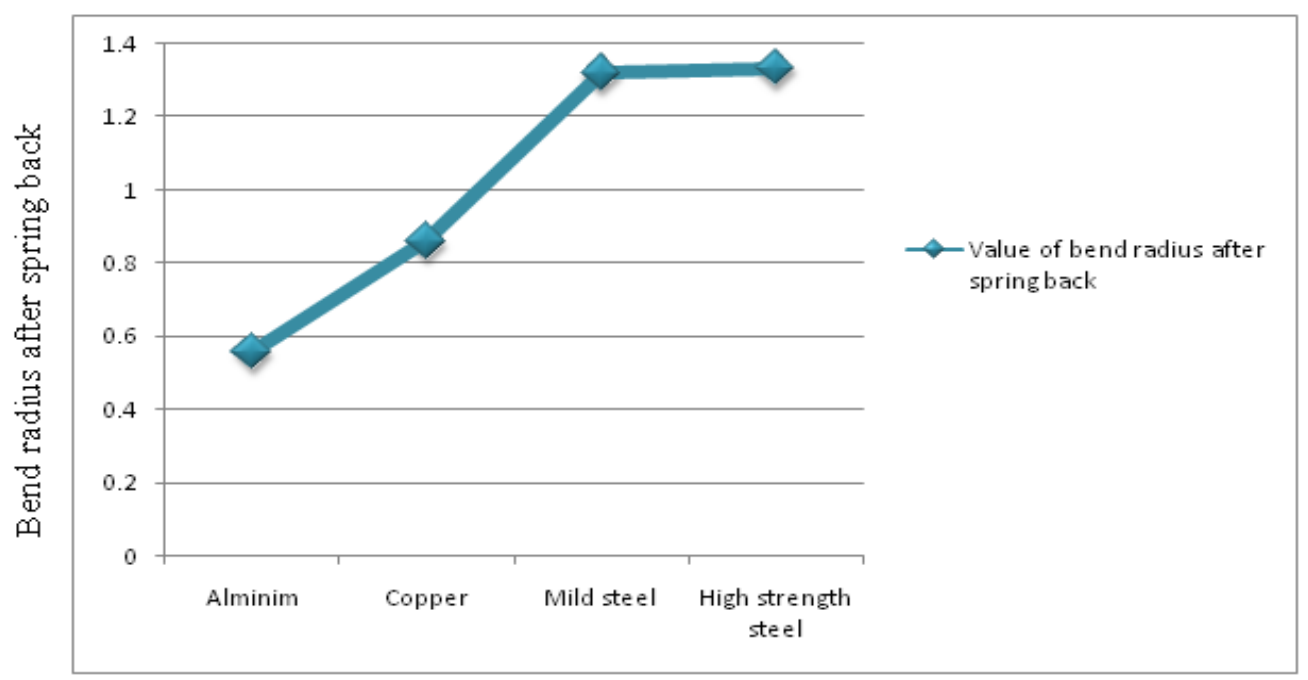

Sheet metal type

Figure 2: The effect of sheet metal type for spring back formation. 


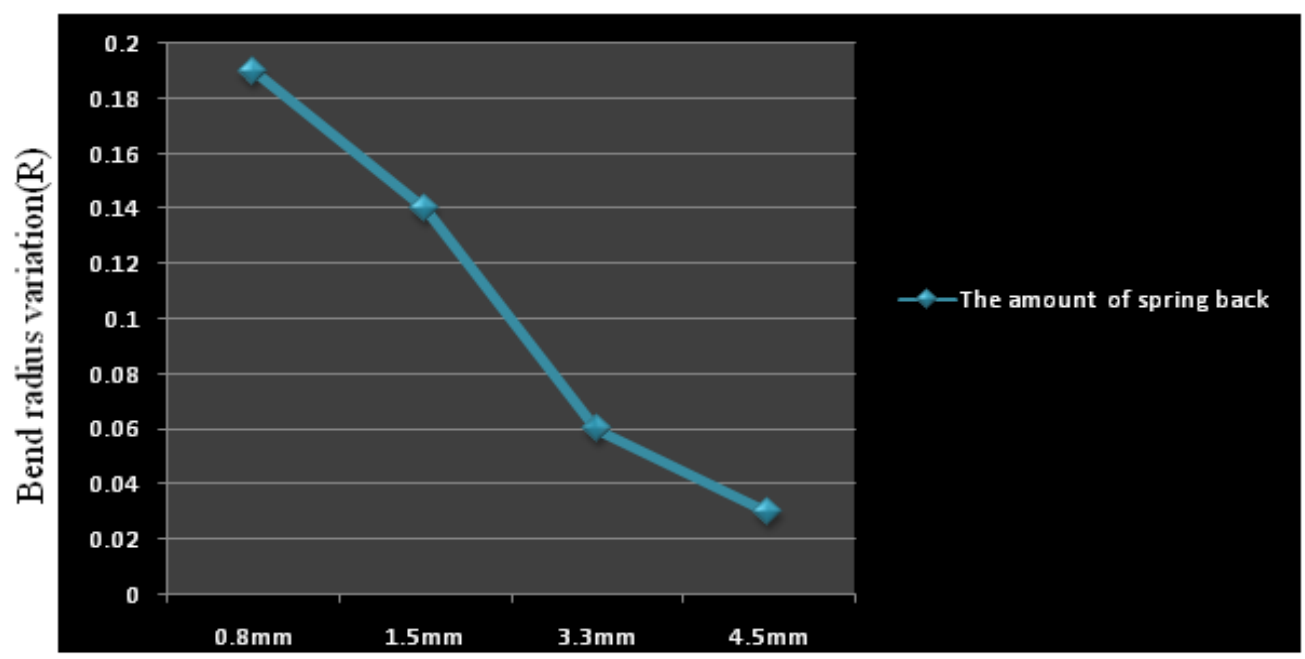

Sheet metal thickness

Figure 3: The effect of sheet metal thickness for spring back formation.

\begin{tabular}{|c|c|c|c|}
\hline \multicolumn{2}{|c|}{ For $\mathbf{9 0 0}, \mathbf{c}=\mathbf{1 . 5 7 0 8}$} & Bending radius $\mathbf{( R ) = R f - R i ~ ( m m ) ~}$ \\
\hline $\mathbf{t}(\mathbf{m m})$ & $\mathbf{R i}(\mathbf{m m})$ & 2.91 & $\mathbf{A l} \mathbf{6 0 6 1}$ \\
\hline $0.8 \mathrm{~mm}$ & 1.60 & 5.46 & 0.19 \\
\hline $1.5 \mathrm{~mm}$ & 3.00 & 12.02 & 0.14 \\
\hline $3.3 \mathrm{~mm}$ & 6.60 & 16.38 & 0.06 \\
\hline $4.5 \mathrm{~mm}$ & 9.00 & 0.03 & \\
\hline
\end{tabular}

Table 2: The effect of thickness for spring back formation.

\begin{tabular}{|c|c|c|c|c|c|c|}
\hline \multicolumn{3}{|c|}{ For 900, c=1.5708 } & & \multicolumn{2}{c|}{$\Delta \boldsymbol{\alpha}$ in degree } \\
\hline $\mathbf{t ~ ( m m )}$ & $\mathbf{R i}(\mathbf{m m})$ & Lb (mm) & Al 6061 & Copper & Mild steel & High strength steel (HSS) \\
\hline 0.8 & 1.6 & 2.91 & 0.49 & 0.12 & 0.11 \\
\hline 1.5 & 3.0 & 5.46 & 0.49 & 0.12 & 0.11 \\
\hline 3.3 & 6.6 & 12.02 & 0.49 & 0.12 & 0.11 \\
\hline 4.5 & 9.0 & 16.38 & 0.49 & 0.12 & 0.11 \\
\hline
\end{tabular}

Table 3: The effect of bending angle for spring back formation.

the equivalent plastic strain achieved in the sheet for different values of die radius through the process. It is noticeable that the area under the equivalent plastic curve for the smaller die radius is larger and the strength of the material also increases which justifies the larger required maximum punch load for it. Our mathematical results in Table 3 and Figure 4 shows that the bending (spring back) angle is reduced when moving from aluminum to high strength steel sheet metal this shows that from material strength and spring back relation thus the spring back increases with decreasing of the bending angle. Form the analysis using Aluminum sheet metal rather than high strength steel for the production process the amount of spring back is reduced by $41 \%$ (Table 4).

Spring back increases with increasing of the die radius. It is noticeable that the stress over the die corner is the most significant factor for governing the amount of spring back. On the other hand, a sheet metal property also says that the strength of the material increases, the spring back also increases. Our analytical result shows that the minimum bend radius increases from aluminum to high strength steel sheet metals. This implies that the spring back increases with increasing of bend radius.

The effects of friction: Tangential forces generated between contacting surfaces are known as frictional forces. These tangential forces resist motion up to a point. The effect of friction on spring back shows that Figure 5 and Table 5 for mild steel sheet metal for constant thickness, increasing the friction coefficient can increase the friction force which implies that during increasing of force sheet metal deformation also increasing. When the sheet metal deformation increases the material will be deformed permanently. But this higher amount of friction force is removing from the material so that the material highly returns to the original position. Due to this reversible changes the spring back increases. Hence, friction have significant factor for spring back formation, in such a way that increasing of friction coefficient spring back increases (Figure 6).

\section{Validation Mathematical Model}

In order to validate Mathematical /or Empirical findings with numerical result is to comparing with different sheet metal type and blank thickness. For constant thickness with different sheet metal type (Al6061,CU,MS,HSS) spring back is predicted analytically 0.557 to $1.333 \mathrm{~mm}$ and on the other hand for the same material (Al) with different sheet metal thickness $(0.8 \mathrm{~mm}, 1.5 \mathrm{~mm}, 3.3 \mathrm{~mm}$ and $4.5 \mathrm{~mm})$ spring back is $0.19-0.03$ is predicted. Numerical result also shows that due to sheet metal thickness variation is range from 0.174 to 0.0474 and 
Citation: Dametew AW, Gebresenbet T (2017) Study the Effects of Spring Back on Sheet Metal Bending using Mathematical Methods. J Material Sci Eng 6: 382. doi: 10.4172/2169-0022.1000382

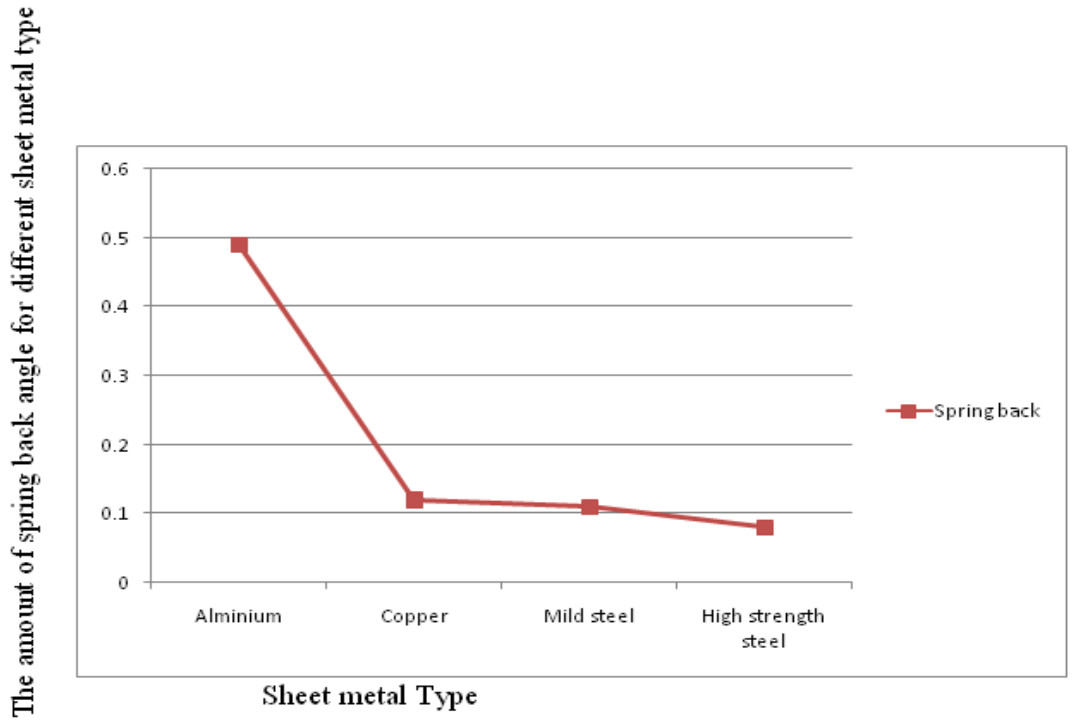

Figure 4: The effect of bending angle for spring back formation.

\begin{tabular}{|c|c|c|}
\hline Sheet metal type & Thickness $(\mathbf{m m})$ & Minimum Bend Radii (Rmin) in mm \\
\hline Aluminium & 4.5 & 0.225 \\
\hline Copper & 4.5 & 0.47 \\
\hline Mild steel & 4.5 & 0.90 \\
\hline High strength steel & 4.5 & 3.15 \\
\hline
\end{tabular}

Table 4: The effect of minimum bend radius for spring back formation.

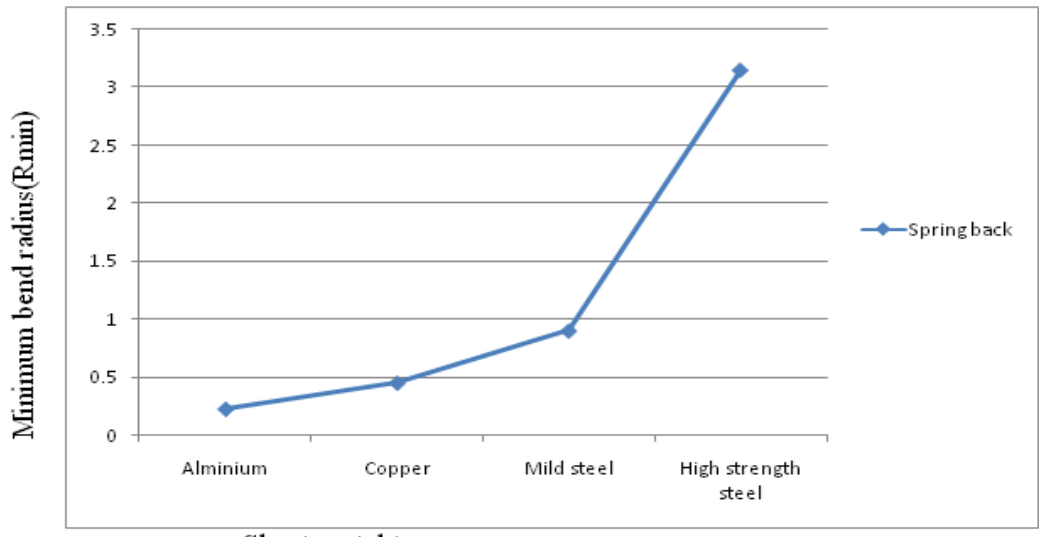

Sheet metal type

Figure 5: The effect of minimum bend radius for spring back formation.

\begin{tabular}{|c|c|c|c|}
\hline Sheet thinness (mm) & Coefficient of friction & Normal force (FN) $\mathrm{Kg} \mathrm{m} / \mathrm{s}^{2}$ & Friction force (FN) $\mathrm{Kg} \mathrm{m} / \mathrm{s}^{2}$ \\
\hline 1.5 & 0.01 & 1.234 & 0.01234 \\
\hline 1.5 & 0.05 & 1.234 & 0.0617 \\
\hline 1.5 & 0.15 & 1.234 & 0.1851 \\
\hline 1.5 & 0.5 & 1.234 & 0.617 \\
\hline
\end{tabular}

Table 5: The effect of Effects of Friction for spring back formation.

\begin{tabular}{|c|c|c|c|c|c|}
\hline Effect & $\begin{array}{l}\text { Empirical/ Analytical } \\
\text { variation }\end{array}$ & Numerical Variation & Empirical Error & $\begin{array}{l}\text { Numerical } \\
\text { Error }\end{array}$ & $\begin{array}{l}\text { Variation between Empirical } \\
\text { with Numerical analysis }\end{array}$ \\
\hline Sheet metal type & 0.557 & 0.56 & -0.0053 & 0.00538 & 0.00008 \\
\hline Sheet Metal Thickness & 0.16 & 0.203 & -0.2118 & 0.269 & 0.057 \\
\hline
\end{tabular}

Table 6: Validation of Empirical with Numerical result. 


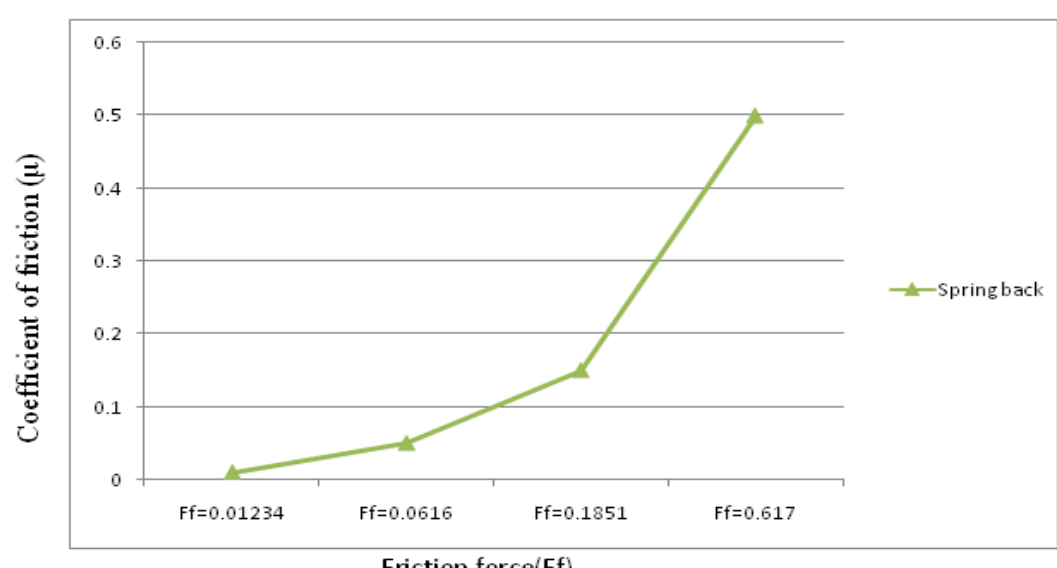

Friction force(Ff)

Figure 6: The effect of Effects of Friction for spring back formation.

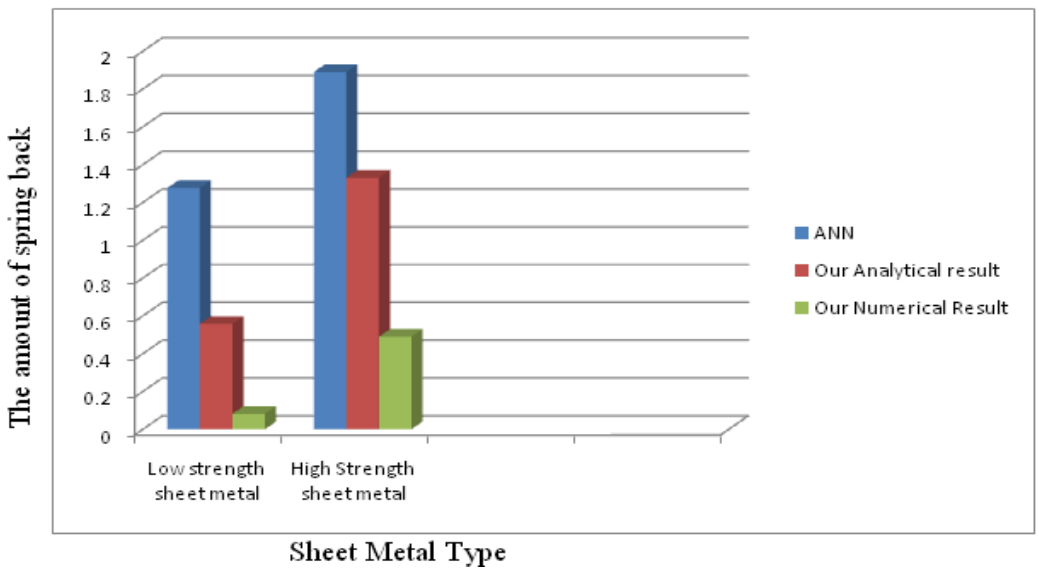

Figure 7: Prediction of spring back in different conditions at different time.

due to sheet metal types the variation is 0.0813 to 0.489 obtained. The error is predicted from different analysis is done by using the following formulas (Table 6).

The Figure 7 shows that the empirical prediction is accurate than the previous analysis, while, this Analytical result is directly show the effects of each parameters. Also this study is better than the previous because we considered more parameters for the during analysis process to the investigations. Since, from these we conclude that this study is done and predicted spring back properly and correctly.

\section{Conclusions and Recommendation}

\section{Conclusions}

In this research work a detailed study of the parameters influencing spring back was conducted using mathematical analysis. The conducted literature review revealed that, although similar studies were conducted in the previous time, and developed models were unable to consider simultaneously all the parameters influencing spring back formation. Accordingly this work is an attempt to study spring back by including more parameters at a time in order to study spring back and predict the amount of spring back in sheet deformation process, thereby optimizing the sheet bending process. For that reason analytical prediction of spring back were conducted in this research work. The developed models were also used for prediction of spring back formation by varying parameters such as: sheet metal material and thickness, coefficient of friction between the die and the material, and tool radius and tool shape. However, from this empirical study the following conclusions were drawn. The result shows that increasing sheet metal thickness from $0.8 \mathrm{~mm}$ to $4.5 \mathrm{~mm}$ the spring back is reduced by $16 \%$. While increasing of sheet metal strength spring back increases however, in these cases more maximum required punch loads are needed. For the effects of material type investigated as, aluminium exhibits lower spring back than mild steel and high strength sheet metals. Since, using aluminium sheet metal instead of high strength sheet metals spring back is reduced by $56 \%$. Although, for decreasing of the tool radius leads to spring back is reduced. Modifying tool shape also changes spring back i.e. using deferential die instead of edge bending die the spring back is reduced by $12 \%$. Increasing of friction coefficient from 0.01 to 0.50 the spring back is increase by $52 \%$. Hence, an optimum value of sheet metal thickness, material type and tool radius should be chosen for reducing of spring back. Finally Utilizing and compensation of tool is considered for optimizing of bending process, when the spring back is reduced, this is also helps to obtain quality sheet metal product.

\section{Recommendation and future works}

Some of the suggestions for further investigations are: 
Citation: Dametew AW, Gebresenbet T (2017) Study the Effects of Spring Back on Sheet Metal Bending using Mathematical Methods. J Material Sci Eng 6: 382. doi: 10.4172/2169-0022.1000382

Page 7 of 7

- To compensate of spring back in the die design using FEM simulations,

- To check the effect of tool material for spring back,

- Development of spring back prediction is conducted in warm and cold sheet metal conditions are also considered.

\section{References}

1. Prabhakar A, Haneef M, Shabbir Ahmed RM (2013) Sheet metal forming analyses with spring back deformation on U-Bends in Isotropic plates. International Journal of Innovative Research in Science, Engineering and Technology 2: 1-9.

2. Andersson A (2007) Numerical and experimental evaluation of springback in advanced high strength steel. Journal of Materials Engineering and Performance 16: 301-307.

3. Kim HS, Koç M (2008) Numerical investigations on springback characteristics of aluminum sheet metal alloys in warm forming conditions. Journal of Materials Processing Technology 204: 370-383.

4. Behrouzi A, Shakeri M, Dariani BM (2008) Inverse analysis of springback in sheet metal forming by finite element method. In Proc. International Conference on Engineering Optimization, pp: 1-5.

5. Kazan R, Firat M, Tiryaki AE (2009) Prediction of springback in wipe-bending process of sheet metal using neural network. Materials \& Design 30: 418-423.

6. Livermore Software Technology Corporation (2009) Ls-Pre Post Metal Forming Simulation (Tutorial Manual-Trimming and spring back).

7. Safaei M, De Waele W, Hertschap K (2011) Finite element analysis of influence of material anisotropy on the springback of advanced high strength steel. In AIP Conference Proceedings 1315: 371-376.

8. Siswanto WA, Omar B (2009) Die surface design optimization accommodating springback assisted by an automatic surface generator. International Journal of Material Forming 2: 797-800. 